\title{
The ongoing globalization needs real and substantial reform of the United Nations
}

\author{
Dusan Soltes ${ }^{1, *}$ \\ ${ }^{1}$ Comenius University, Odbojarov str. 10, 82505 Bratislava, Slovakia.
}

\begin{abstract}
Research background: This paper has been prepared as a result of our ongoing research on various aspects of ongoing globalization and regional integration and as a power point presentation has been presented at the recent ACUNS - Academic Council on the United Nations International Conference that has been carried out as a virtual event I June 2021.

Purpose of the article: The main purpose of this paper is to present our proposal for the reform of the United nations system in order it could better be serving to the contemporary globalized and regionally integrated world now consisting of 193 member states in difference to only 51 original founding members of the United Nations in 1945.

Methods: As for the applied methodology we have used the critical analysis of the existing UN system to identifying its strong and weak characteristics and on the basis of that to formulate some recommendation in order to adjust the overall UN system to the real needs of the current globalized world being dominated by the ongoing regional integrations, multinational corporations, various political and security structures and last and not least the $\mathrm{UN}$ has to return back to the full respect towards the first sentence of its Charter i.e.: "WE the peoples of the UN..."

Findings \& Value added: In view of this, we could state that the results of our research as formulated in the part 3 of this paper could be considered as our proposal for adjusting the current $\mathrm{UN}$ system and all its various specialized agencies to the real needs of the contemporary globalized world in such a way like reforming the UN Security Council, the UN General assembly as a kind of the global Parliament, selection and election of the UN secretary General, revitalization of the activity of the UN regional economic commissions, etc.
\end{abstract}

Keywords: United Nations; UN Security Council; UN General Assembly; Permanent members of the UN Security Council; UN Charter.

JEL Classification: $F 55 ; F 68 ; H 7$

* Corresponding author: author@email.org 


\section{Introduction and some background to $\mathrm{UN}$ reforms}

It is already almost seventy six years when after the 2nd World War (2WW) has been established on 24 October 1945 the new global organization of the United Nations (UN) at the founding international conference held in San Francisco in the United States. The name of the host country has to some extent given also the name to this new international organization and as its seat has been chosen the New York City and since that time this is still the same although the world has substantially changed since the UN (3) as the most important and biggest international organization has been established almost seventy six year ago.

Especially it has to be taken into account that the world has substantially changed since year 1945 when the UN has been established in particular shortly after the horrors of the $2 \mathrm{WW}$ with the main mission and task to prevent another such horrors to be repeated in the future again. If we are dealing with the UN first of all we have to take into account that in time when the UN has been established at the particular international conference at San Francisco. That conference has been attended and the UN has been established by fifty one founding members. The rest of the current $\mathrm{UN}$ member states was at that time not eligible to become the UN member states as at that time they were mostly colonies of some colonial powers especially those from Europe like the UK, France, Belgium, Portugal, etc. In addition there were also other countries that were not allowed to become founding UN member states due to their status of aggressors during the $2 \mathrm{WW}$ as e.g. Germany, Italy, Japan, etc.

In other to realize how the world has changed substantially changed since the UN establishment in 1945 it is necessary to realize that while original number of the UN member states has been only those above stated 51 countries so until now the membership of the UN has increased to today's 193 countries (1) so it is almost four times. Almost similarly enormous growth of the total world population has increased from the original 2,5 billion people in 1945 to the current almost nine billion of world population, what is also almost four time growth. But if we compare this enormous growth in the numbers of the UN member states together with the growth of the world population we may see that many UN fundamental organs and functions has not been changing accordingly and mostly they remained the same as they were established originally in year 1945 mostly at that time after the still very emotional horrors of the $2 \mathrm{WW}$.

If we compare basically two most important organs of the UN system i.e. the |General Assembly (GA) and the UN Security Council (SC) we see one substantial difference among the development of them between the years 1945 and now of 2021. While the General Assembly has been growing in the same pace as the UN membership has been growing so within those seventy six years the GA has grown from original 51 members to the current 193 countries. However, the Security Council during all that period of time and the growth of membership remained the same. There are still only original five permanent members with the absolute veto power. They are in alphabetic order as follows:

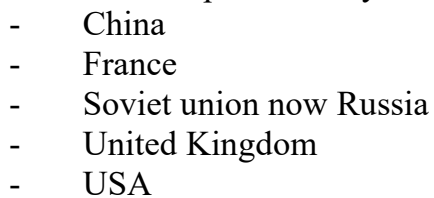

It means that any of these above five permanent members can individually veto and thus block adoption of any decision of the Security Council (8) and in such a case any such decision and/or proposal is automatically nullified and cannot be implemented in practice.

In this connection we have to realize that those five permanent members from the beginning of their existence have been authorized and mandated by the UN Charter to be responsible first of all for maintaining and guaranteeing the permanent peaceful world and 
thus directly or indirectly support peaceful world and thus creating and securing conditions for the peaceful sustainable development all over the globe.

However, from the very beginning of its existence the selection of the these UN Security Council five permanent members with the absolute veto power i.e. any individual permanent member can veto any decision of the UN SC without necessity to get support from any other permanent members or from other ten rotating members of the Security Council. Hence in principle it means that any permanent member can veto any decision even in case if all other permanent members and all 10 rotating members of the SC are in favor of any such decision.

In this connection we have to realize that from the very beginning the selection of those five permanent members have been accompanied by a very serious controversies and criticism regarding their so powerful veto power. The main critics was as follows:

In case of China the main problem has been that for relatively long period of time it has been represented not by the Peoples Republic of China (PRC) but separated province of Taiwan that even until now is by the PRC considered as to be its temporary separated but otherwise integral part of the mainland China similarly as it was previously the case of Hong Kong or Macao

As far as France as the permanent member, the main controversy has been that France was not participating in any of the meetings and negotiations on the post war world that were held in Tehran or Yalta yet before the end of the $2 \mathrm{WW}$ by the so called big Troika i.e. the Soviet Union, United Kingdom and the USA. In addition France (2) was not even the part of the so called second front that has been launched in 1944 by an enormous invasion of the armies especially of the USA and the UK but also numerous other overseas countries even such like Canada, Australia, New Zealand, India etc. but not France!? Moreover, France has played very negative role at the Munich conference in 1938 when it agreed that Nazi Germany could without fighting occupy the former Czechoslovakia and what directly led to the subsequent launching the $2 \mathrm{WW}$. But then when the UN has been established the France unexpectedly has become one of the UN SC permanent members with the full veto power.

Although nobody has been denying the most important role of the Soviet Union in victory over the fascist Germany in the $2 \mathrm{WW}$, but on the other hand there were just some reservations regarding the Stalin dictatorship that has caused death not only of millions of innocent Soviet citizens but also some controversies regarding the prewar pact with the Nazi Germany that indirectly led to the direct launching the $2 \mathrm{WW}$ by attacks against Poland not only from Germany but also from the side of the Soviet Union.

In the case of the USA the main critics has been the relatively late entry of the country to the $2 \mathrm{WW}$ in principle only after Japan has unexpectedly attacked the Pearl Harbor and destroyed the entire important navy basis there. In addition, there was also some controversy regarding atomic bombing of Hiroshima and Nagasaki that was considered as unnecessary as Japan at that time was already on the verge of absolute defeat and moreover the both cities have not represented any militarily justified targets.

The role of the UK as a permanent member of the UN SC was also questioned especially in connection of its also shameful role at the Munich conference in 1938 where without any fighting was former Czechoslovakia given to fascist Germany in order as they were arguing together with France that they have by this pleasing Hitler prevented the war in Europe what of course was not the case and it has only further supported military ambitions of the fascist Germany to go to the $2 \mathrm{WW}$.

\section{Some main selected problems and weaknesses of the current UN system}

If we would like to carry out some innovation and adjustment of the current UN to the conditions of the current world with the current $193 \mathrm{UN}$ member states we have to go back to the fundamental UN documents especially to its UN Charter (5) where have been enshrined 
all basic principles and goals of the UN organization. In this connection first of all we have to take into account the first sentence of the UN Charter that is stating:

"We the peoples of the United Nations..." what cannot be understood in any other way than that it is up to the people of now already of all 193 countries of the UN to be at helm of the world destiny and all decisions, activities of the UN. In view of that all of them have to be carried out by the world people and for them all without any derogations, discriminations as it is also stated in the basic UN documents like e.g. . in the UN Declarations on the fundamental human rights (6) as accordingly we all are equal. Of various other fundamental UN principles we have to state that every people have right to self-determination what means e.g. that also people of Scotland in the UK or of Catalunya in Spain have this one of the fundamental principles as enshrined in the UN Charter. And any such attempts as we see from the side of the UK Government and especially of Spain to scandalize and to brand those self-determinations movements by people of Scotland or even more of Catalunya is just a clear violation of the UN Charter and those governments have to be without any hesitation be punished by the UN for not respecting the fundamental principles of the UN Charter regarding the right for self- determination of all people.

Other important principle of the UN is that all problems and potential conflicts among and between UN member states have to be solved in the peaceful and cooperative way what in principle it means that first of all the members of the UN Security Council and in particular its five permanent members have to be in the front line of keeping world peace and peaceful cooperation and relations between and among all UN member states.

Unfortunately, as in many other problem areas also in this case the reality and practice is not as it has to be according to the mandate and duties of the UN Security Council and in general also the UN itself as such. We could bring numerous examples since the inception of the UN where especially five permanent members have been involved in various regional and subregional conflicts like e.g. in Vietnam, Afganistan, Syria, Iraq, Korea, former Yugoslavia, Hungary, former Czecho-Slovakia, in various African countries, etc. where and in many other various conflicts right the permanent UN Security Council members have been directly involved and instead of calming the conflicts in many cases they have directly been actively contributing to them.

Other negative aspect of the functioning of the permanent members of the UN SC has been the process of decolonization (7) as one of the most important missions and duties of the UN in general and that being one of the most important aspects of practical implementation of the principles of self-determinations as being enshrined from the beginning of the UN existence. In this respect some evident progress has been achieved and thanks to that now we have $193 \mathrm{UN}$ member states instead of original 51 when the rest of those current new members used to be colonies and otherwise dependent countries and territories especially governed by the main colonial powers from Europe especially the UK or France as the permanent members of the UN SC but also some other European colonial powers like Belgium, the Netherlands, Portugal, Spain, etc. However, to some evident paradox especially the UK and France again as countries with the veto power in the UN SC are still keeping some territories outside of their own territories but now as various so called overseas departments, autonomous regions, etc. as it is still e.g. the case of Gibraltar, the Falklands (Malvinas in Spanish), British Guyana, Surinam, Greenland, French Guyana, French Polynesia, etc.

Even from these several examples it is evident that the UN especially now in the era of the ongoing globalization and regional integration and their deepening over the entire globe is already not always meeting all its main objectives and missions as stipulated in its UN Charter and its main duty regarding the protection of the world peace but also various other key documents and missions as stipulated in and about by UN Declaration on the fundamental human rights, Process of decolonization and the Right for self-determination for 
every people as well as for peaceful development and cooperation, etc. And last but not least it is necessity to respect the mission of the UN according to that first sentence of the UN Charter i.e. "We the peoples of the United Nations...." What in practical terms means nothing more or less that the UN and the world have to be governed by the world people of all those various 193 member states.

In the next part we are presenting some proposals for innovations and reforming the entire UN system as much as possible according to this one but the most important sentence of the UN Charter that since its inception has been serving as a kind of the Constitution of the UN system.

\section{Some selected proposals for the UN reform for its mission in the era of the current ongoing globalization and regional integration}

In view of the above previous parts of this paper here we are trying to present some of the most important key changes and reforms in order to make the entire UN system better to suite to the challenges of the contemporary globalized world and ongoing further deepening and widening not only globalization but also regional integration. As we know the whole world is divided to various and quite many regional groups of states. One of them and being directly an integral part of the UN system itself is represented by six UN regions administered by the particular UN Economic Commissions as they now exist i.e. the ECE, ESCAP, ECLA, ECA, ECWA. However, in addition to this regionalization of the otherwise globalized world, we have to take into account also various other regional integration groups of states like e.g. the EU, NAFTA, ASEAN, AU, GCC, MERCOSUR, (4) etc.

Hence for any future reforms in the UN system it is necessary more attention to pay also to these regional entities either those corresponding to the UN regional commissions and/or also those various other regional groups of states. Accordingly, in our proposed reforms for the future UN system we are trying to take into account also these existing regional structures of the contemporary otherwise more and more globalized world. In this respect our main proposed reforms are as follows:

If we are basing our reforms on the fundamental principles of the UN i.e. "We the people of the United Nations..." then it is clear that especially such an important organ like the UN Security Council needs substantial reform and innovation. It is absolutely unacceptable that the veto power there have two countries i.e.. the UK and France with their individual population less than $1 \%$ (one per cent!) of the current global population.

- $\quad$ It is true that when the UN has been established in 1945 with only 51 countries the rest of the world up to current 193 member states was mostly the world of colonies belonging mostly to these two at that time colonial powers of the UK and France. Hence, in this view this still existing structure and functioning of the UN SC needs substantial changes. One potential solution would be that in case of France, the veto power in the UN SC would be transferred to the EU as such, as after all also France is one of the countries participating in the EU Common Foreign and security Policy or currently to EEAS - European External Action Service. The mandate of the UK in the UN SC has just to be abolished.

It is an unwanted and unaccepted paradox that veto power belongs to representative of less than one per cent of the global population while such big countries representing several times large population of the UN like India, Brazil, Indonesia, Nigeria, etc. have no word in many key decisions of such an important organ of the entire UN system like is it represented by the UN SC. Therefore our main proposal in this respect is to substantially change the composition of the permanent members of the UN SC in such a way it will better represent the peoples of the UN and also existing regional structure of the current global world. It is necessary that every one of the UN regions would have at least one permanent member with a veto power in order to represent there directly interests of the particular 
region. Accordingly, the Europe would be represented by the EU, Africa by Nigeria, ESCAP region by China, India and Indonesia, Latin America by Brazil in addition to the USA as the still most developed country, Russia as the largest country in the world and China as the most populous country in the world.

The entire system of veto power needs to be reformed as well in such a way that not any single country could block any key decision of the UN SC. In principle it has to be changed to a system with weighting principle respecting the weight of population of let say the veto could be applied only when such a proposal is supported e.g. by more than a half of the world population so no single country even such a large one in terms of population like e.g. China or together with India could not veto any UN SC decision, resolution, etc.

The substantial reform is needed also regarding the UN General Assembly (GA) that should function as the world parliament and accordingly also all its decision have to be reorganized in such a way as it is common in case of national parliaments or as a more close example is the European Parliament of the EU. Basically, we could imagine that in this way the UN SC and UN GA would be functioning as the upper and lower chambers of the UN Parliament and thus removing one of the criticism i.e. that the entire UN global governance system is lacking the democratic fundamentals and has been continuing with often criticized the current democratic deficit.

The substantial changes are also needed in the post of the UN Secretary General as the top administrator of the entire UN system. While currently it is fully in the hands of the UN SC permanent members who often are vetoing potential candidates so for the future we would recommend to base it on the rotation basis of candidates from those existing six UN regions. In addition, there should be only one perhaps slightly extended term but the candidate from individual UN region would then be approved by the new UN SC i.e. it would be not possible that a single permanent member could veto or block or otherwise to make any obstructions regarding the candidate for UN Secretary General as proposed on the rotating basis from his/her UN region. It could be also acceptable to submit two or more candidates and then it would be upon the UN GA or UN SC to select one of them for such a prestigious post as is the post of the UN Secretary General .

It is necessary to reform still existing system of decolonization in such a way that in all still existing dependent or otherwise not sovereign countries and territories there would be under the authority of the UN conducted fair and free referendums so again the people of those still existing depended territories would directly by themselves decide what future they want to have. In no way it is acceptable that some national or federal governments like e.g. in case of Spain and Catalunya could declare the leaders of the independence movement as traitors, criminals and to jail them for their application of the one of the main principles of the UN i.e. "We the peoples..." are those to decide on their future on the basis of the right to self-determination.

The jurisdiction of the UN Court of Justice in Den Haag has to be extended and strengthened against all UN member states without any exemption, derogations, etc. It is necessary that every UN member state will be fully and without any exemption under the jurisdiction of this world highest court and its ruling and decisions have to be fully respected and implemented into the practice of every particular country to which such a decision or ruling has been addressed. Basically, we could in this case use the example of the European Court of Justice in Luxemburg whose decisions have to be fully respect by all EU member states as otherwise there are various ways and means how to achieve the particular compliance

The UN personnel management and hiring system has to be made more attractive also for the specialists and staff members also from the most developed countries as the current system in many cases is especially attractive for specialists from low and lower salaries countries but not for the top specialists from the rich countries and/or for well paid 
professionals from multinational corporations, etc. In order to strengthen the relation of the individual UN agencies and the UN in general with the outside world it is recommended to limit the tenure of any UN staff to maximum e.g. of 5 years. Afterwards, any of them has to go to work for at least 3-5 years to somewhere outside of the UN and then only be eligible to apply again and if successful could return back to work for the UN and/or its specialized agencies. Otherwise, there is still existing danger that the UN system will be loosing its direct touch with the outside real work, etc.

It is necessary to reactivate the roles of all six regional UN Economic Commissions especially regarding their cooperation and harmonization of various development and other activities with the regional integration blocks like e.g. between the EU and the UNECE in Europe and/or between the ECA i.e. Economic Commission for Africa and AU - African Union moreover in this case when both of them are in the same city in Addis Ababa, Ethiopia. All that in order to better utilize various development oriented funds and programs and to avoid any very often existing duplicities, multiplicities, etc. in various development activities. For example it is well known that the EU by itself belongs among the largest donors of various its development projects but definitely it would be more efficient if its projects and similar activities would be harmonized with the UN regional economic commissions

In order to make the activities of the various specialized UN agencies like e.g. ILO, ITU, UNICEF, UNIDO, UNCTAD, WHO, etc.(9) more efficient and costs beneficial it would be worth to move some of such UN development agencies from their current headquarters in New York, Geneva, Vienna, etc. closer to the main objects their development activities being mostly in the developing and least developed countries in Africa, Asia, Latin America, etc. In the past it was necessary in order to achieve more closer relations between and among individual UN development agencies but now in the era of the dominating ICT technologies all over the globe it is not necessary to keep individual UN agencies only at several exclusive hubs of New York, Geneva, Vienna, etc. It is really an unwanted paradox that in Africa as a continent which is mostly in the focus of the development activities by various UN agencies are at the moment in addition to ECA - Economic Commission for Africa in Addis Ababa in Ethiopia functioning only two of the many UN agencies viz. the UNCHS (HABITAT) and UNEP both in Nairobi, Kenya.

As for the UN family of the specialized agencies it is recommended to carry out a serious audit of all of them and if necessary to reformulate their missions as in quite many cases there have been existing some serious overlapping and in various other of them there were completely changed their main functions and orientations as e.g. the UNCTAD (10) is in addition to its original mission oriented towards development of the world trade it become a more visible function on monitoring of global regional and national trends in FDI in the form of publishing its Annual Report on the global and regional trends in FDI. Or in case of the UNIDO the focus from the original orientation on industrial development now we may see also in its orientation towards alternative sources of energy and its impact on environment that is also a mission of the UNEP, etc.

For more efficient functioning of all various UN development and specialized agencies it would be beneficial if they would be not fully dependent regarding their budget exclusively and/or mostly on the contributions from their member states. In this respect as a potentially very good example could be serving the UNICEF that in addition to its budget being created by the contributions from its member states has also its own source of income through the production and sale of various well known souvenirs, post cards, toys, publications for kids, etc. On the same principles all various other UN agencies could be functioning more independently from the member states that very often misuse their financial contributions to be effecting those UN agencies more negatively than it is acceptable for independence of the UN and its specialized agencies and their activities. 


\section{Conclusion}

In conclusion we could state that the main purpose of this our paper has been to adjust the existing UN system as being established at the end of the $2 \mathrm{WW}$ to the practical needs of the contemporary globalized world being dominated by the now already 193 independent states and altogether representing current UN family members. The leading purpose of our approach to the problems or reforming and innovating the current Un has been to bringing it to the original mission of the Un to serving to the world people as it has been enshrined in the first sentence of the UN Charter i.e. "We the peoples of the United Nations...". In view of this key principle in the previous part of this paper we are presenting results of our long term ongoing research how and in what directions it is necessary to revitalize, innovate and to some extent substantially reform some of the most important organs and functions of the overall UN system with its family of the specialized agencies.

\section{References}

1. About the United Nations Membership. Avaliable at : About UN Membership | United Nations

2. D-Day and France. Avaliable at: https://www.nga.gov/features/monuments-men/d-dayand-france.html

3. Everyone's United Nations. A Handbook on the United Nations its structure and Activities, United Nations Publications. New York.

4. Regional Trading Blocks and Economic Integration. Avaliable at https://chaturvedimayank.wordpress.com/2017/10/28/.

5. UN (1945). The United Nations Charter. Avaliable at https://www.un.org/en/aboutus/un-charter.

6. UN (1945). United Nations Universal Declaration of Human Rights. Avaliable at: https://www.un.org/en/about-us/universal-declaration

7. UN.(1945). United Nations and Decolonization. Avaliable at: https://www.un.org/dppa/decolonization

8. United Nations Security Council. Avaliable at: https://www.un.org/securitycouncil

9. United Nations and its Specialized Agencies and related Inter-governmental Organizations. Avaliable at : Specialized Agencies | United Nations

10. UNCTAD World Investments Report 2021. Avaliable at https://investmentpolicy.unctad.org/news/hub/1674/. 